\title{
Adherence to highly active antiretroviral therapy in a tertiary care hospital in West Bengal, India
}

Rajib Saha ${ }^{1}$, MBBs, MD, Indranil Saha ${ }^{2}$, MBBS, MD, Aditya Prasad Sarkar ${ }^{1}$, MBBS, MD, Dilip Kumar $\underline{\text { Das }}^{3}$, MBBS, MD, Raghunath Misra ${ }^{1}$, MBBS, MD, Krishnadas Bhattacharya ${ }^{1}$, MBBS, MD, Rabindra Nath Roy ${ }^{1}$, MBBS, MD, Abantika Bhattacharya ${ }^{1}$, MBBS, MD

INTRODUCTION The introduction of highly active antiretroviral therapy (HAART) for the treatment of human immunodeficiency virus (HIV) infection and acquired immunodeficiency syndrome (AIDS) has led to the reduction of mortality and the improvement of the quality of life of people living with HIV/AIDS (PLWHA). The present study was conducted to determine the pattern of adherence to HAART among PLWHA, and to assess the factor(s) affecting nonadherence, if any.

METHODS This study was a hospital-based analytical, cross-sectional epidemiological study conducted between July and October 2011. A total of 370 adult HIV-positive patients registered in the Antiretroviral Therapy Centre of Burdwan Medical College and Hospital, West Bengal, India, were included. Nonadherence was defined as missing at least a single dose of medicine within the last four days. Data was analysed using the Statistical Package for the Social Sciences version 19.0 (IBM Corp, Armonk, NY, USA).

RESULTS A total of $87.6 \%$ of patients were found to be adherent to HAART. Principal causes of nonadherence were forgetting to take medicine (70.2\%), being away from home (65.2\%), and busyness with other things (64.7\%). Multivariate logistic regression analysis revealed that nonadherence was significantly associated with a positive family history of HIV/AIDS (odds ratio [OR] 16;95\% confidence interval [CI] 2.2-114.3; $p=0.01$ ), occurrence of side effects with HAART (OR 9.81; 95\% Cl 1.9-51.7; $\mathrm{p}=0.01)$ and employment (OR 5.93; 95\% Cl 1.5-23.2; $\mathrm{p}=0.01$.

CONCLUSION Although overall adherence was high, the factors that affect nonadherence can be addressed with proper counselling and motivation of patients and their family members. Adherence to HAART could delay the progression of this lethal disease and minimise the risk of developing drug resistance.

Keywords: adherence to HAART, ART Centre, nonadherence to HAART, PLWHA

\section{INTRODUCTION}

According to the 2010 report by the Joint United Nations Programme on human immunodeficiency virus (HIV) and acquired immunodeficiency syndrome (AIDS), approximately 2.4 million people in India were living with HIV and AIDS; this is equal to $0.3 \%$ of the estimated world HIV burden. ${ }^{(1)}$ Among the adults in India, the prevalence of HIV was $0.29 \%$. In an estimate made in $2007,10 \%$ of the people living with HIV/AIDS (PLWHA) in India were residing in West Bengal, and the state is designated as a state with a low prevalence of HIV, according to sentinel surveillance data.(2) Based on the annual report by the West Bengal State AIDS Prevention and Control Society, made available on 31 March 2010, a total of 17,694 registered cases and 6,095 PLWHA are present in West Bengal. West Bengal has 9 antiretroviral therapy (ART) centres and 17 link ART centres for the provision of antiretroviral treatment. ${ }^{(3)}$

The introduction of highly active antiretroviral therapy (HAART) in the treatment of HIV has shown dramatic results, leading to the reduction of mortality and the improvement of the quality of life of PLWHA. ${ }^{(4,5)}$ However, it has also surfaced new problems such as the development of drug-resistant viral strains and the transmission of resistant strains due to suboptimal adherence in resource-poor settings. ${ }^{(6)}$ In order to prevent the emergence of resistant viral strains, and thus maintain the effectiveness of HAART in the treatment of HIV/AIDS, high levels of motivation and adherence are required from the patient. ${ }^{(7)}$ It has been demonstrated that if adherence to HAART improved by $10 \%$, disease progression will be reduced by $21 \%{ }^{(8)}$ Adherence to HIV treatment regimen is defined as taking all the prescribed pills at the right time, in the right doses and in the right way. ${ }^{(9)}$ After CD4 count, adherence is considered the second strongest predictor of disease progression and chance of survival. ${ }^{(10)}$ Nonadherence raises the risk of therapy failure and developing drug resistance. ${ }^{(11,12)}$

Although the national ART programme in India was launched in April 2004, there remains limited research and information regarding the levels of adherence and the predictors of suboptimal adherence to treatment among PLWHA. As this information is also lacking in West Bengal, the present study was conducted to determine the pattern of adherence and the possible factors associated with nonadherence to HAART, if any, in a nodal ART centre attached to a tertiary care hospital situated in the Burdwan district in West Bengal, India.

\footnotetext{
${ }^{1}$ Department of Community Medicine, Burdwan Medical College and Hospital, ${ }^{2}$ Department of Community Medicine, IQ City Medical College \& IQ City Narayana Hrudayalaya Hospital, ${ }^{3}$ Department of Community Medicine, North Bengal Medical College and Hospital, West Bengal, India

Correspondence: Dr Rajib Saha, AD-234, Rabindrapally, Krishnapur, Kolkata 700101, West Bengal, India. dr.rajsaha@gmail.com
} 


\section{METHODS}

The present study is a hospital-based observational, analytical, cross-sectional epidemiological study conducted between July and October 2011 in the ART centre of Burdwan Medical College and Hospital, a tertiary care hospital in West Bengal, India. All PLWHA patients from this centre aged $\geq 18$ years, and who have been receiving HAART for at least six months were included in the study.

The ART centre of Burdwan Medical College and Hospital has been functioning since December 2005, and is the only nodal centre in the entire district of Burdwan, West Bengal. This centre provides HAART free of charge and has the relevant resources for CD4 count estimation, counselling sessions and regular check-ups. According to the June 2011 monthly report of this ART centre, 2,248 PLWHA were registered, out of which 977 were adults who attended follow-up regularly.

According to the World Health Organization, adherence to HAART in developing countries is $60 \%-80 \% .{ }^{(13)}$ Assuming $60 \%$ adherence and an absolute precision of $5 \%$, the total sample size required was calculated to be 368 (formula used: $\mathrm{n}=\mathrm{z}^{2} \mathrm{pq} / \mathrm{e}^{2} ;$ where $\mathrm{n}=$ sample size, $\mathrm{z}=$ value of standard normal deviate $=1.96$ at $95 \%$ confidence interval $[\mathrm{Cl}], \mathrm{p}=$ prevalence of adherence, $q=1-p$, and $e=$ absolute precision). ${ }^{(14)}$ During the study period, data was collected on three (alternate) days every week. Days of data collection were varied in consecutive weeks to reduce the bias for day-specific outpatient department attendance. On the days of data collection, all patients who were eligible for inclusion in the present study were interviewed consecutively in private (after obtaining written consent), until the target sample size was reached. Thus, complete enumeration method was adopted. A total of 370 patients were included in the study; non-willing patients, patients who were unable to communicate (e.g. deaf and dumb), and seriously ill patients were excluded from the study. This study was approved by Ethics Review Committee of Burdwan Medical College and Hospital.

Patients were first briefed about the purpose of the study and assured regarding the confidentiality of the data given. After written consent was obtained from the participants, they were interviewed with the help of a predesigned and pretested schedule, which includes the Adult AIDS Clinical Trial Group adherence questionnaire (ACTGAQ). ${ }^{(15)}$ ACTGAQ is a selfreporting tool used for assessing adherence to HAART. This tool has been extensively used in countries like the United States, ${ }^{(15)}$ northern Italy, ${ }^{(16)}$ Sub-Saharan Africa, ${ }^{(17)}$ and Denmark. ${ }^{(18)}$ It has also been used in many regions in India. ${ }^{(19-21)}$

HAART-related profiles of the patients were taken from ART cards and medical records. Data regarding sociodemographic characteristics and adherence to HAART were collected using in-depth interviews. The information obtained through the interviews was checked and verified by pill-count. The information from the in-depth interviews was used only if no discrepancy was noted. In the present study, all pill-counts corroborated with the information obtained from the in-depth interviews. Family members of the patients were also interviewed to crosscheck the data obtained regarding adherence.

In this study, adherence is defined as a self-report of not missing a single dose of medication over the previous four days. ${ }^{(15)}$ The time period used to define adherence to HAART varies with different studies, ranging from one day to one month. ${ }^{(22)}$ Since dementia is common among PLWHA, in order to avoid recall bias, a short period of history (i.e. four days) was used for measuring adherence in the present study. Furthermore, if a patient missed a single dose of HAART out of the total eight doses within a four-day schedule, the patient's adherence would be $<95 \%$. This, according to the guidelines set by the National AIDS Control Programme of India (95\% has been set as the adherence level), ${ }^{(23)}$ would mean that the patient is considered nonadherent to HAART.

Data was compiled and analysed using Microsoft Excel (Microsoft, Redmond, WA, USA) and the Statistical Package for the Social Sciences version 19.0 (IBM Corp, Armonk, NY, USA). Central tendency of data was represented using means, but in the presence of an outlier (i.e. wild data point), median was calculated. Standard deviation was used to represent the dispersion of data. The association between different sociodemographic and clinical variables in relation to nonadherence to HAART were determined using Pearson's chi-square test; Yate's corrected chi-square and Fisher's exact test were applied in appropriate cases. Independent variables that were found to be statistically significant in bivariate analysis were considered for application in the logistic regression model to determine the important predictors of nonadherence, with nonadherence (yes or no) as the dependent variable. A p-value of $\leq 0.05$ was considered statistically significant.

\section{RESULTS}

The mean age of the 370 patients enrolled in the present study was $33.5 \pm 8.5$ years. Most of the patients were male and Hindu $(58.4 \%$ and $88.9 \%$, respectively), $63.2 \%$ were from rural areas and $50.8 \%$ were educated up to secondary school (i.e. Standard V to X). The percentages of patients who were married, widowed and separated were $83.3 \%, 12.7 \%$ and $1.4 \%$, respectively. In our study population, $33.0 \%$ of patients were unemployed, $10.3 \%$ were truck drivers and $8.4 \%$ were commercial sex workers. A majority of the patients were smokers and $44.1 \%$ had addictions (Table I).

Median time of HIV diagnosis was 19 (range 6-72) months, median time of starting HAART was 12 (range 6-48) months, and median CD4 cell count just prior to starting of HAART was 241 (range 54-484) cells/ $\mu \mathrm{l}$. In terms of treatment, about $44.1 \%$ of patients were on zidovudine (ZDV), lamivudine (3TC) and nevirapine (NVP) regimen, while $28.4 \%$ were on stavudine (d4T), 3TC and NVP regimen. The percentage of patients on ZDV, 3TC and efavirenz (EFV) regimen was $16.8 \%$, while $10.8 \%$ were on $\mathrm{d} 4 \mathrm{~T}, 3 \mathrm{TC}$ and EFV regimen. Concurrent opportunistic 
Table I. Adherence to highly active antiretroviral therapy according to the sociodemographic characteristics of the study population $(n=370)$.

\begin{tabular}{|c|c|c|c|}
\hline \multirow[t]{2}{*}{ Characteristic } & \multicolumn{2}{|c|}{ No. of patients (\%) } & \multirow{2}{*}{$\begin{array}{l}\text { Test of significance } \\
\left(\chi^{2} ; \mathbf{d f} ; \mathbf{p} \text {-value }\right)\end{array}$} \\
\hline & Adherent $(n=324)$ & Nonadherent $(n=46)$ & \\
\hline Age (yrs) & & & $\chi^{2} 13.1 ;$ df $3 ; p<0.001$ \\
\hline $31-40$ & $118(36.4)$ & $13(28.3)$ & \\
\hline $41-50$ & $60(18.5)$ & $2(4.3)$ & \\
\hline$>50$ & $11(3.4)$ & $0(0)$ & \\
\hline Male & 192 (59.3) & $24(52.2)$ & \\
\hline Female & $132(40.7)$ & $22(47.8)$ & \\
\hline Religion & & & $\chi^{2} 12.0 ;$ df $1 ; p<0.001$ \\
\hline Hindu & $295(91.0)$ & $34(73.9)$ & \\
\hline Muslim & $29(9.0)$ & $12(26.1)$ & \\
\hline Education level & & & $\chi^{2} 11.7 ;$ df $4 ; p=0.02$ \\
\hline Illiterate & $22(6.8)$ & $8(17.4)$ & \\
\hline Secondary & $163(50.3)$ & $25(54.3)$ & \\
\hline Higher secondary & $10(3.1)$ & $0(0)$ & \\
\hline Graduate & $32(9.9)$ & $0(0)$ & \\
\hline Residence & & & $\chi^{2} 23.7 ;$ df $1 ; p<0.001$ \\
\hline Rural & $190(58.6)$ & $44(95.7)$ & \\
\hline Urban & $134(41.4)$ & $2(4.3)$ & \\
\hline Employment status & & & $\chi^{2} 5.77 ;$ df $1 ; p=0.02$ \\
\hline Employed & $210(64.8)$ & $38(82.6)$ & \\
\hline Unemployed & $114(35.2)$ & $8(17.4)$ & \\
\hline Socioeconomic status* & & & $\chi^{2} 140 ;$ df $4 ; p<0.001$ \\
\hline Upper class & $71(21.9)$ & $2(4.3)$ & \\
\hline Upper middle & $73(22.5)$ & $2(4.3)$ & \\
\hline Lower middle & $78(24.1)$ & $3(6.5)$ & \\
\hline Upper lower & $90(27.8)$ & $11(23.9)$ & \\
\hline Lower & $12(3.7)$ & $28(60.9)$ & \\
\hline Unmarried & $10(3.1)$ & $0(0)$ & \\
\hline Widowed & $46(14.2)$ & $1(2.2)$ & \\
\hline Separated & $5(1.5)$ & $0(0)$ & \\
\hline Addiction & & & $\chi^{2} 0.75 ;$ df $1 ; p=0.39$ \\
\hline Present & $140(43.2)$ & $23(50.0)$ & \\
\hline Absent & $184(56.8)$ & $23(50.0)$ & \\
\hline
\end{tabular}

infections were reported in $24.6 \%$ of patients, $49.7 \%$ of patients had a family history of HIV, and $43.8 \%$ had experienced side effects following HAART (Table II).

In our study, 324 of the $370(87.6 \%)$ patients were adherent to HAART (i.e. did not miss a single dose over the last four days), and the remaining 46 (12.4\%) patients were nonadherent. About $45.7 \%$ of the patients never missed any dose throughout HAART. Further analysis revealed that $14.9 \%, 25.9 \%$ and $39.5 \%$ patients had missed their dose of HAART within the last one week, one month and three months, respectively. In the last four days, about $7.0 \%$ patients missed their full day's medication. While a majority $(64.6 \%)$ of patients followed the drug schedule most of the time (within the last four days), the drug schedule was followed all the time by only $13.5 \%$ of patients. Based on the self-reports and pill-counts, we found that $11.1 \%$ patients had $<80 \%$ adherence to HAART, and $7.0 \%$ were found to have $<50 \%$ adherence (Table III).

A total of $201(54.3 \%)$ patients missed at least one dose during their entire HAART regimen. Major reasons cited for missing doses were: (a) forgot to take medicine (70.1\%); (b) busy with other things (64.7\%); (c) forgot to bring medicines when away from home $(65.2 \%)$; (d) change in daily routine (40.3\%); and (e) feeling overwhelmed/depressed (15.4\%). Other reasons cited for missing HAART doses were a fear of side effects $(10.0 \%)$, ran out of pills $(5.0 \%)$, felt good $(3.0 \%)$, and felt sick or ill (5.0\%) (Table IV). Bivariate analysis revealed that nonadherence was significantly higher $(p<0.05)$ among patients who were aged 18-30 years, Muslims, illiterate, of a lower socioeconomic class, employed, and living in rural areas. Nonadherence was also observed to be commonly associated with some disease-related factors, such as HIV diagnosis and initiation of HAART within the past year, history of HIV among family members, absence of family members taking HAART, experience of side effects, CD4 count within 200-300 cells/ $\mu \mathrm{L}$, and efavirenz and stavudine-based HAART regimens (i.e. d4T, 3TC and EFV regimens) (Tables I \& II).

The logistic regression model was significant, as evident from omnibus chi-square test $(p<0.001)$. Collectively, all the 
Table II. Adherence to highly active antiretroviral therapy (HAART) according to the clinical profile of the patients $(n=370)$.

\begin{tabular}{|c|c|c|c|}
\hline \multirow[t]{2}{*}{ Variable } & \multicolumn{2}{|c|}{ No. of patients (\%) } & \multirow[t]{2}{*}{ Test of significance } \\
\hline & Adherent $(n=324)$ & Nonadherent $(n=46)$ & \\
\hline Time since HIV diagnosis (yrs) & & & $\chi^{2} 8.2 ;$ df $3 ; p=0.04$ \\
\hline$\leq 1$ & $142(43.8)$ & $23(50.0)$ & \\
\hline $1-2$ & $111(34.3)$ & $21(45.7)$ & \\
\hline $2-4$ & $60(18.5)$ & $2(4.3)$ & \\
\hline$>4$ & $11(3.4)$ & $0(0)$ & \\
\hline Time since starting HAART (yrs) & & & $\chi^{2} 7.63 ;$ df $2 ; p=0.02$ \\
\hline$\leq 1$ & $183(56.5)$ & $33(71.7)$ & \\
\hline $1-2$ & $99(30.6)$ & $13(28.3)$ & \\
\hline$>2$ & $42(13.0)$ & $0(0)$ & \\
\hline Concurrent opportunistic infection & & & $\chi^{2} 0.38 ;$ df $1 ; p=0.54$ \\
\hline Present & $78(24.1)$ & $13(28.3)$ & \\
\hline Absent & $246(75.9)$ & $33(71.7)$ & \\
\hline Continued risk behaviour(s) post HAART & & & Fisher's exact test $p=0.09$ \\
\hline Present & $21(6.5)$ & $0(0)$ & \\
\hline Absent & $303(93.5)$ & $46(100.0)$ & \\
\hline History of HIV among family members & & & $\chi^{2} 14.6 ;$ df $1 ; p<0.001$ \\
\hline Present & $149(46.0)$ & $35(76.1)$ & \\
\hline Absent & $175(54.0)$ & $11(23.9)$ & \\
\hline $\begin{array}{l}\text { History of HAART among family } \\
\text { members* }\end{array}$ & & & $\chi^{2} 18.4 ;$ df $1 ; p<0.001$ \\
\hline Present & $61(40.9)$ & $1(2.9)$ & \\
\hline Absent & $88(59.1)$ & $34(97.1)$ & \\
\hline Side effect(s) following HAART & & & $\chi^{2}$ 35.9; df $1 ; p<0.001$ \\
\hline Present & $123(38.0)$ & $39(84.8)$ & \\
\hline Absent & $201(62.0)$ & $7(15.2)$ & \\
\hline Relief from symptoms after starting & & & Fisher's exact test $p=0.62$ \\
\hline HAART & & & \\
\hline Present & $314(96.9)$ & $46(100.0)$ & \\
\hline Absent & $10(3.1)$ & $0(0)$ & \\
\hline CD4 count just prior to HAART (cells $/ \mu \mathrm{L}$ ) & & & $\chi^{2} 26.7 ;$ df $3 ; p<0.001$ \\
\hline$\leq 100$ & $73(22.5)$ & $1(2.2)$ & \\
\hline $100-200$ & $31(9.6)$ & $0(0)$ & \\
\hline $200-300$ & $190(58.6)$ & $45(97.8)$ & \\
\hline$>300$ & $30(9.3)$ & $0(0)$ & \\
\hline HAART regimen & & & $\chi^{2} 75 ;$ df $3 ; p<0.001$ \\
\hline $\mathrm{d} 4 \mathrm{~T}, 3 \mathrm{TC}, \mathrm{NVP}$ & $104(32.1)$ & $1(2.2)$ & \\
\hline d4T, 3TC, EFV & $19(5.9)$ & $21(45.7)$ & \\
\hline ZDV, ЗTC, NVP & $142(43.8)$ & $21(45.7)$ & \\
\hline ZDV, 3TC, EFV & $59(18.2)$ & $3(6.5)$ & \\
\hline
\end{tabular}

${ }^{*}$ Data only available for 184 patients (149 adherent, 35 nonadherent).

$\chi^{2}$ : chi-square; 3TC: lamivudine; d4T: stavudine; df: degrees of freedom; EFV: efavirenz; HIV: human immunodeficiency virus; NVP: nevirapine; ZDV: zidovudine

independent variables could explain between $30.6 \%$ and $57.9 \%$ variance of the dependent variable (i.e. nonadherence), as evident from analyses using Cox \& Snell and Nagelkerke $\mathrm{R}^{2}$. The regression model is able to correctly predict $65.2 \%$ of nonadherence and $100 \%$ of the adherence to HAART. Overall, the model predicts $95.7 \%$ of adherence property correctly, as calculated in the classification table of the logistic regression model. The positive beta coefficients for positive family history of HIV, presence of side effects with HAART and positive employment status mean that the chances of nonadherence in a patient increases with the presence of one or more of these independent variables. We found that patients who had family members who were also suffering from HIV were 16 times more likely to be nonadherent to HAART, as compared to patients with no history of HIV among their family members (odds ratio [OR] 16; 95\% Cl 2.2-114.3; $p=0.01$ ). Patients who had experienced side effects of medication were
9.81 times more likely to be nonadherent to HAART, compared to those who had not experienced any side effects (OR 9.81; 95\% Cl 1.9-51.7; p = 0.01). Patients who were employed were found to be 5.93 times more likely to be nonadherent than unemployed patients (OR 5.93; 95\% Cl 1.5-23.2; $\mathrm{p}=0.01)($ Table $\mathrm{V})$.

\section{DISCUSSION}

The present study was designed to determine the pattern of adherence to HAART and the factors associated with nonadherence in a nodal ART centre in a district of West Bengal, India, where HAART is supplied free of charge. Our results revealed a high level of adherence $(87.6 \%)$ among adult PLWHA, similar to that reported in other studies conducted in resource-limited settings in India $(\approx 90 \%)^{(25)}$ and those conducted in other countries (e.g. Senegal $83 \%-95 \%{ }^{(26)}$ and South Africa $\left.93.5 \%{ }^{(27)}\right)$. In a meta-analysis of ART programmes 
Table III. Distribution of male and female patients according to their pattern of adherence to highly active antiretroviral therapy $(n=370)$.

\begin{tabular}{|c|c|c|c|c|c|c|c|c|}
\hline \multirow[t]{2}{*}{ Gender } & \multicolumn{4}{|c|}{ Level of adherence 4 days before the survey } & \multicolumn{4}{|c|}{ Drug schedule followed throughout treatment } \\
\hline & $\geq 95 \%$ & $80 \%-94 \%$ & $51 \%-79 \%$ & $\leq 50 \%$ & Sometimes & $\begin{array}{l}\text { About half } \\
\text { of the time }\end{array}$ & $\begin{array}{l}\text { Most of } \\
\text { the time }\end{array}$ & All the time \\
\hline Male & 192 & 3 & 13 & 8 & 10 & 27 & 149 & 30 \\
\hline Female & 132 & 2 & 2 & 18 & 8 & 36 & 90 & 20 \\
\hline Total (\%) & $324(87.6)$ & $5(1.4)$ & $15(4.1)$ & $26(7.0)$ & $18(4.9)$ & $63(17.0)$ & $239(64.6)$ & $50(13.5)$ \\
\hline
\end{tabular}

Table IV. Reasons given for missing doses of highly active antiretroviral therapy $(n=201)$.

\begin{tabular}{lc}
\hline Reason for missing doses & No. (\%) \\
\hline Away from home & $131(65.2)$ \\
Busy with other things & $130(64.7)$ \\
Simply forgot & $141(70.1)$ \\
Too many pills to take & $10(5.0)$ \\
To avoid side effects & $20(10.0)$ \\
Change in daily routine & $81(40.3)$ \\
Fell asleep/slept through dose time & $69(34.3)$ \\
Felt sick or ill & $10(5.0)$ \\
Felt depressed/overwhelmed & $31(15.4)$ \\
Ran out of pills & $10(5.0)$ \\
Felt good & $6(3.0)$ \\
\hline
\end{tabular}

conducted in resource-poor settings ${ }^{(28)}$ and in studies conducted in Chennai, India, ${ }^{(29,30)}$ patients receiving HAART free of charge were reported to have a higher adherence to HAART than paying patients. Contradictory findings were reported by Sarna et al's study. ${ }^{(31)}$ In that study, which was conducted in Pune and Delhi, a much lower (81\%) adherence to HAART was observed among patients receiving free HAART (through an insurance programme) than paying patients. ${ }^{(31)}$

In the present study, PLWHA aged $<30$ years were more nonadherent to HAART than PLWHA aged $\geq 30$ years. Similar findings of poorer adherence in younger age groups, especially those aged $<35$ years, have also been reported in other studies. ${ }^{(32,33)}$ Gender was not found to be associated with adherence in our study, similar to that reported by Fogarty et al. ${ }^{(34)}$ The level of education of PLWHA was also not found to be significantly associated with nonadherence in the present study, as was also reported by Cauldbeck et $\mathrm{al}^{(35)}$ and Paasche-Orlow et al. ${ }^{(36)}$ Contrary to the findings of the study conducted in Pune and Delhi, ${ }^{(31)}$ the PLWHA in the present study who were employed were more nonadherent to HAART than those who were unemployed. Probable causes of nonadherence among employed PLWHA are busy duty schedules in the workplace and/or forgetfulness. The present study's finding of greater nonadherence to HAART among PLWHA who had experienced side effects to HAART was also observed in other studies. ${ }^{(35,37)}$ Due to the fear of undesirable side effects, many patients discontinued their medications. A statistically significant association was found between nonadherence of PLWHA and a positive family history of HIV, consistent with the findings of a study conducted in Nigeria by Igwegbe et al. ${ }^{(38)}$ It seems that when PLWHA have family members who are also suffering from HIV, they lose their hope in life and are thus more reckless, leading to a higher incidence of nonadherence. In the present study's logistic regression analysis, a positive family history of HIV was found to be the strongest predictor of nonadherence to HAART.

In the present study, forgetfulness was the principal reason for missing doses in HAART - a finding that is in line with that of other studies. ${ }^{(5,18,38,39)}$ A majority of PLWHA forgot to take their medicines due to busy schedules, forgetting to bring medicines when away from home, and changed daily routines. Patients on EFV-based regimens were found to be more nonadherent to HAART. This is likely due to the neuropsychiatric side effects associated with EFZ, such as sleep disturbances and depression. Sleep disturbances and depression were observed to be causes of missed doses in HAART in the present study ( $34.3 \%$ and $15.4 \%$, respectively). The central nervous system (CNS) side effects associated with EFZ use are common among CYP2B6 carriers. Thus, the higher level of nonadherence among patients on EFZ-based regimens in our study could be explained by the higher prevalence of cytochrome $2 \mathrm{~B} 6$ mutations in the Indian population, ${ }^{(40)}$ as well as the fact that the present study had no scope for EFZ dose reduction ${ }^{(41)}$ according to CYP2B6 carrier status of the patients.

One limitation of the present study is that it was conducted only on patients who attended the ART centre on a regular basis. Patients who dropped out permanently and could not be traced were not included in the study. Therefore, although these patients may have characteristics that differ from those who attended the ART centre regularly, these group of patients were not represented in the data analysis.

Although the overall adherence to HAART was found to be high among the patients from the ART centre in the present study, many of the causes identified to result in nonadherence could be addressed, even in a clinical setting, for better outcome. The factors found to be associated with nonadherence in the present study, such as a positive family history of HIV and the presence of side effects with HAART, highlight that the quality of counselling in the ART centre needs to be improved. To increase adherence to HAART, patients can be encouraged to use the alarm systems available on their cell phones, or any other device that would be carried with 
Table V. Logistic regression model for the predictors of nonadherence to highly active antiretroviral therapy.

\begin{tabular}{|c|c|c|c|c|c|c|c|}
\hline Variable & B & SE & Wald & df & Sig. & $\operatorname{Exp}(B)$ & $95 \% \mathrm{Cl}$ for $\operatorname{Exp}(\mathrm{B})$ \\
\hline \multicolumn{8}{|l|}{ Step 1} \\
\hline Age & -0.10 & 0.09 & 1.29 & 1 & 0.26 & 0.91 & $0.77-1.07$ \\
\hline Religion & 1.44 & 0.63 & 5.22 & 1 & 0.22 & 0.90 & $0.73-14.41$ \\
\hline Education & 1.31 & 1.83 & 0.51 & 1 & 0.47 & 3.71 & $0.10-133.13$ \\
\hline Marital status & -0.84 & 1.65 & 0.26 & 1 & 0.61 & 0.43 & $0.02-11.29$ \\
\hline Time since HIV diagnosis & -0.03 & 0.03 & 1.03 & 1 & 0.31 & 0.97 & $0.92-1.03$ \\
\hline Family history of HIV & 2.77 & 1.01 & 7.62 & 1 & 0.01 & 16.10 & $2.20-114.32$ \\
\hline Family history of HAART & 0.75 & 1.18 & 0.41 & 1 & 0.52 & 2.12 & $0.21-21.41$ \\
\hline Side effect(s) & 2.28 & 0.85 & 7.25 & 1 & 0.01 & 9.81 & $1.86-51.70$ \\
\hline CD4 count & -0.01 & 0.01 & 0.77 & 1 & 0.38 & 0.99 & $0.98-1.01$ \\
\hline Socioeconomic status & 0.83 & 0.44 & 3.35 & 1 & 0.04 & 2.22 & $0.95-5.24$ \\
\hline Employment & 1.78 & 0.74 & 6.52 & 1 & 0.01 & 5.93 & $1.51-23.23$ \\
\hline Regimen & 0.47 & 0.87 & 0.29 & 1 & 0.59 & 1.62 & $0.29-8.79$ \\
\hline Constant & -4.71 & 2.64 & 3.19 & 1 & 0.07 & 0.01 & - \\
\hline
\end{tabular}

df: degrees of freedom; HIV: human immunodeficiency virus; SE: standard error

them during their working hours, to provide timely reminders on taking medication. Adherence can also be improved by providing counselling to the family members of patients, irrespective of the patients' family history of HIV. This is because supportive care from family members may improve patients' adherence. Although self-reporting and pill-count are cost-effective techniques to measure adherence, it would be beneficial if the ART centre adopted the use of modern techniques, such as viral load assessment and the Medication Event Monitoring System, which is more specific and less erroneous. All these steps may help to delay the progression of the disease in patients, as well as minimise the risk of developing drug resistance in the community.

\section{REFERENCES}

1. UNAIDS. UNAIDS report on the global AIDS epidemic 2010 [online]. Available at: http://www.unaids.org/globalreport/global_report.htm. Accessed April 24, 2013.

2. Government of India. HIV Sentinel Surveillance and HIV estimation in India 2007, A Technical Brief. New Delhi: NACO, Ministry Of Health and Family Welfare, 2008.

3. West Bengal State AIDS Prevention and Control Society. Annual report 2009-10 [online]. Available at: www.wbhealth.gov.in/wbsapcs/report/ Annual\%20Report09-10Final.pdf. Last accessed April 10, 2012.

4. Mannheimer SB, Matts J, Telzak E, et al. Quality of life in HIV-infected individuals receiving antiretroviral therapy is related to adherence. AIDS Care 2005; 17:10-22

5. Tadios Y, Davey G. Antiretroviral treatment adherence and its correlates among people living with HIV/AIDS on highly active antiretroviral therapy in Addis Ababa, Ethiopia. Ethiop Med J 2006; 44:237-44.

6. Blower S, Ma L, Farmer P, Koenig S. Predicting the impact of antiretroviral in resource-poor settings: prevention of HIV infection whilst controlling drug resistance. Curr Drug Targets Infect Disord 2003; 3:345-53.

7. Paterson DL, Swindells S, Mohr J, et al. Adherence to protease inhibitor therapy and outcomes in patients with HIV infection. Ann Intern Med 2000; 133:21-30.

8. Nischal KC, Khopkar U, Saple DG. Improving adherence to antiretroviral therapy. Indian J Dermatol Venereol Leprol 2005; 71:316-20.

9. Carter M. Adherence-information series for HIV-positive people. 3rd ed. London: NAM, 2005.

10. Hogg RS, Heath K, Bangsberg D, et al. Intermittent use of triple-combination therapy is predictive of mortality at baseline and after one year of follow-up. AIDS 2002; 16:1051-8.

11. Adam BD, Maticka TE, Cohen JJ. Adherence practices among people living with HIV. AIDS Care 2003; 15:263-74.

12. Malcolm SE, Ng J, Rosen RK, Stone VE. An examination of HIV/AIDS patients who have excellent adherence to HAART. AIDS Care 2003; 15:251-61.

13. World Health Organization. Adherence to HIV treatment, Geneva; 2003. (Department of HIV/AIDS unpublished internal technical brief).
14. Lameshow S, Lwanga SK. Sample size determination in health studies, a practical manual. Geneva: WHO, 1991.

15. Chesney MA, Ickovics JR, Chamben DB, et al. Self-reported adherence to antiretroviral medications among participants in HIV CLINICAL trial: The AACTG adherence instruments. Patient Care Committee and Adherence Working Group of the Outcomes Committee of the Adult AIDS Clinical Trial Group (AACTG). AIDS Care 2000; 12:255-66.

16. Maggiolo F, Ravasio L, Ripamonti D, et al. Similar adherence rates favor different virologic outcomes for patients treated with nonnucleoside analogues or protease inhibitors. Clin Infect Dis 2005; 40:158-63.

17. Unge C, Södergård B, Marrone G, et al. Long-term adherence to antiretroviral treatment and program drop-out in a high-risk urban setting in sub-Saharan Africa: a prospective cohort study. PLoS One 2010; 5:e13613.

18. Barfod TS, Sørensen HT, Nielsen H, Rodkjaer L, Obel N. "Simply forgot" is most frequently stated reason for missed doses of HAART irrespective of degree of adherence. HIV Med 2006; 7:285-90.

19. Sarna A, Pujari S, Sengar AK, et al. Adherence to antiretroviral therapy \& its determinants among HIV patients in India. Indian J Med Res 2008; 127:28-36.

20. Shah B, Walshe L, Saple DG, et al. Adherence to antiretroviral therapy and virologic suppression among hiv-infected persons receiving care in private clinics in Mumbai, India. Clin Infect Dis 2007; 44:1235-44.

21. Ekstrand ML, Chandy S, Heylen E, Steward W, Singh G. Developing useful highly active antiretroviral therapy adherence measures for India: the Prerana study. J Acquir Immune Defic Syndr 2010; 53:415-6.

22. Mills EJ, Nachega JB, Buchan I, et al. Adherence to antiretroviral therapy in sub-Saharan Africa and North America: a meta-analysis. JAMA 2006; 296:679-90.

23. Bachani D, Rewari BB. Antiretroviral therapy: practice guidelines and National ART Programme. J Indian Med Assoc 2009; 107:310-4.

24. Sundar Lal, Adarsh, Pankaj. Textbook of Community Medicine. 3rd ed. New Delhi: CBS Publishers \& Distributors Pvt Ltd, 2011: 17-20.

25. Wanchu A, Kaur R, Bamberry P, Singh S. Adherence to generic reverse transcriptase inhibitor-based antiretroviral medication at a tertiary centre in North India. AIDS Behav 2007; 11:99-102.

26. Lanièce I, Ciss M, Desclaux A, et al. Adherence to HAART and its principal determinants in a cohort of Senegalese adults. AIDS 2003; 17(Suppl 3):S103-8.

27. Orwell C, Bangsberg DR, Badri M, Wood R. Adherence is not a barrier to successful antiretroviral therapy in South Africa. AIDS 2003; 17:1369-75.

28. Ivers L, Kendrick D, Doucette K. Efficacy of antiretroviral therapy programs in resource-poor settings: a meta-analysis of the published literature. Clin Infect Dis 2005; 41:217-24.

29. Safren S, Kumarasamy N, James R, et al. ART adherence, demographic variables and CD4 outcome among HIV-positive patients on antiretroviral therapy in Chennai, India. AIDS Care 2005; 17:853-62.

30. Kumaraswamy N, Safren SA, Raminani SR, et al. Barriers and facilitators to antiretroviral medication adherence among patients with HIV in Chennai, India: a qualitative study. AIDS Patient Care STDS 2005; 19:526-37.

31. Sarna A, Gupta I, Pujari S, et al. Examining adherence and sexual behaviour among patients on antiretroviral therapy in India. Horizons Final Report Washington, DC: Population Council; 2006.

32. Murri R, Ammassari A, De Luca LA, et al. Self-reported non adherence with antiretroviral drugs predicts persistent condition. HIV Clin Trials 2001; 2:323-9. 
33. Frank I. Once-daily HAART: toward a new treatment paradigm. J Acquir Immune Defic Syndr 2002; 31(suppl 1):S10-15.

34. Fogarty L, Roter D, Larson S, et al. Patient adherence to HIV medication regimens: a review of published and abstract reports. Patient Educ Couns 2002; 46:93-108.

35. Cauldbeck MB, O'Connor $\mathrm{C}, \mathrm{O}^{\prime}$ Connor $\mathrm{MB}$, et al. Adherence to antiretroviral therapy among HIV patients in Bangalore, India. AIDS Res Ther 2009; 6:7

36. Paasche-Orlow MK, Cheng DM, Palepu A, et al. Health literacy, antiretroviral adherence, and HIV-RNA suppression: a longitudinal perspective. J Gen Intern Med 2006; 21:835-40.

37. Mills EJ, Nachega JB, Buchan I, et al. Adherence to antiretroviral therapy in sub-Saharan Africa and North America: a meta-analysis. JAMA 2006; 296:679-90.
38. Igwegbe AO, Ugboaja JO, Nwajiaku LA. Prevalence and determinants of non-adherence to antiretroviral therapy among HIV positive pregnant women in Nnewi, Nigeria. Int J Med Med Sci 2010; 2:238-45.

39. Amberbir A, Woldemichael K, Getachew S, Girma B, Deribe K. Predictors of adherence to antiretroviral therapy among HIV-infected persons: a prospective study in Southwest Ethiopia. BMC Public Health 2008; $8: 265$.

40. Lee LS, Soon GH, Teo YY. Inter-ethnic differences in efavirenz CNS toxicity - role of cytochrome P450 2B6 polymorphisms. BMC Infect Dis 2012; 12(suppl 1): O17.

41. Gatanaga H, Hayashida T, Tsuchiya K, et al. Successful efavirenz dose reduction in HIV type 1-infected individuals with cytochrome P450 2B6 *6 and *26. Clin Infect Dis 2007; 45:1230-1237. 